\title{
To the Point Article
}

Digestion

\section{Treatment of Oesophageal Varices in Liver Cirrhosis}

\author{
Tilman Sauerbruch $^{a}$ Florence Wong ${ }^{b}$ \\ ${ }^{a}$ Department of Medicine, University of Bonn, Bonn, Germany; ${ }^{b}$ Division of Gastroenterology, Department of \\ Medicine, University of Toronto, Toronto, ON, Canada
}

\section{Keywords}

Oesophageal varices . Bleeding prophylaxis and treatment . Liver cirrhosis

\begin{abstract}
Background: The development of cirrhosis with resultant portal hypertension can lead to oesophageal varices at a rate of $7 \%$ per annum. Bleeding from varices happens when the portal pressure is $\geq 12 \mathrm{~mm} \mathrm{Hg}$ and can threaten life. Summary: Eliminating the aetiology of cirrhosis is a pivotal step to prevent the formation of varices. In patients with established varices, primary prophylaxis with non-selective beta blockers (NSBB) may slow down the progression of varices and prevent the first variceal bleed. NSBB, similar to other agents such as renin/angiotensin blockers, statins, and rifaximin, may have the additional advantage of blunting inflammatory stimuli, which can contribute to the progression of varices. Variceal band ligation is an alternative for primary bleeding prophylaxis with excellent results. Any acute variceal bleed should be managed with band ligation after careful resuscitation. Early pre-emptive transjugular intrahepatic portosystemic shunt (TIPS) in decompensated cirrhotic pa-
\end{abstract}

\section{KARGER}

(๑) 2018 S. Karger AG, Basel

E-Mail karger@karger.com

www.karger.com/dig tients is very effective in controlling the bleeding and improves survival. Secondary prophylaxis against further variceal bleeding using NSBB and band ligation is recommended in most other patients. TIPS may be considered in appropriate patients as a secondary prophylaxis against recurrent variceal bleed. Future research should be directed towards the prevention of varices and targeting inflammation to reduce cirrhotic complications. Key Messages: Treatment strategies depend on the stage the patient is at along the natural history of varices: NSBB or band ligation for primary prophylaxis; band ligation or early TIPS for acute bleed; and a combination of NSBB + band ligation or TIPS for secondary prophylaxis (Fig. 1).

(c) 2018 S. Karger AG, Basel

\section{Formation of Varices and Occurrence of Variceal Bleeding}

Liver cirrhosis is the most common cause of obstruction to blood flow in the portal venous system, leading to the formation of collateral vessels returning the blood to the right atrium. These collaterals - mainly located with- 
Fig. 1. Treatment of esophageal varices.

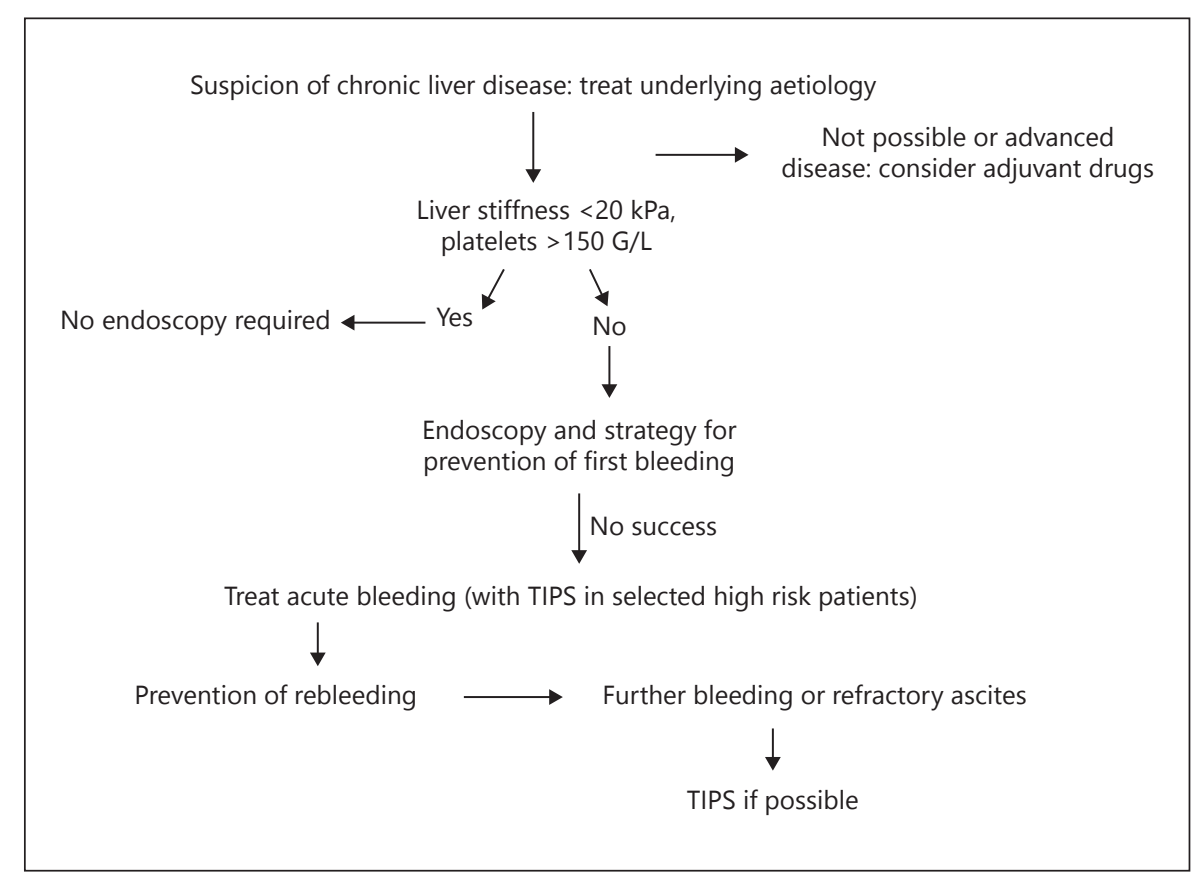

in the mucosa and submucosa $[1,2]$ of the distal oesophagus, the gastroesophageal junction or the gastric fundus - may rupture and cause life threatening bleeding. It is assumed that once the portal pressure surpasses $10 \mathrm{~mm}$ $\mathrm{Hg}$, varices develop. Further elevation of the portal pressure to $12 \mathrm{~mm} \mathrm{Hg}$, as assessed by measuring the gradient of the blood pressure between the portal and the inferior vena cava (HVPG) [3], is the precondition for variceal bleeding. This, together with the development of ascites, jaundice and encephalopathy, are signs of decompensation in liver cirrhosis. The potential of bleeding occurs beyond a threshold of $12 \mathrm{~mm} \mathrm{Hg}$. Besides the blood pressure within the vessel, the risk of bleeding is determined by morphological parameters (variceal size and location) $[1,2,4]$. In compensated cirrhosis without oesophageal varices, such collaterals develop at a rate of $7-8 \%$ per year [5].

\section{Treatment of Cirrhosis Aetiology}

Liver fibrosis and hepatic inflammation promote portal hypertension and formation of varices. Thus, the prime goal of treating varices is timely treatment of the cirrhosis aetiology, be it excessive alcohol intake - the most prevalent cause of liver cirrhosis - or the presence of hepatotropic viruses. In patients with chronic liver disease, this requires diagnosis of the aetiology at the pre-cirrhotic stage, prior to the development of significant portal hypertension [6]. Several tools for non-invasive early diagnosis of fibrosis are available [7], enabling early treatment for the prevention of cirrhosis and its complications [8-10]. Unfortunately, patients with liver cirrhosis are often referred after cirrhosis is well established [11], especially in case of alcohol use disorders. Despite this, there are steps that can be taken to prevent progression of cirrhosis such as more attention to life style, since being overweight, having diabetes and excess alcohol intake share pathways for the pathogenesis of chronic liver disease, cirrhosis and portal hypertension [12].

\section{Blunting Formation of Varices}

In the case of advanced liver disease, elimination of aetiology of cirrhosis remains the key factor in the management of these patients. However, intrahepatic inflammatory stimuli and portal hypertension can persist [13, 14]. Larger trials are required to investigate whether patients successfully treated for hepatitis B and hepatitis C infections and those with non-alcoholic steatohepatitis with persistent metabolic damage can profit from adjuvant medications, such as non-selective beta blockers (NSBB) [15], renin-angiotensin system inhibitors [16], statins [17] or rifaximin [18], alone or in combination 
$[19,20]$. All these drugs blunt inflammatory stimuli and reduce portal pressure.

\section{Assessment of Varices and Bleeding Risk}

Although endoscopy remains the gold standard for diagnosis of esophageal varices - absent in about half of the patients at the time of diagnosis of cirrhosis [21] - it is now accepted that this procedure can be avoided in patients with liver stiffness of $<20 \mathrm{kPa}$ as assessed by controlled transient elastography and a platelet count above $150 \times 10^{9} / \mathrm{L}$ [22]. Most of these patients have compensated clinically unapparent cirrhosis (Child-Pugh group A). In all other patients, endoscopy determines further therapy. The size of esophageal varices and the so-called red colour sign on the vessels (red wales and cherry red spots) - partly corresponding to intraepithelial tiny blood channels and high intravariceal blood pressure [23] - as well as concomitant gastric varices [4] are important morphological parameters that predict variceal bleeding, especially if combined with advanced degree of decompensation (high Child-Pugh score) and aetiology (with higher bleeding risk in alcoholic vs. non-alcoholic cirrhosis) $[4,24]$.

\section{Prevention of First Bleeding}

Patients with small varices, compensated cirrhosis (Child-Pugh class A) and no red wale signs do not require measures for primary bleeding prophylaxis, but follow-up endoscopy should be performed for timely assessment of progression to a higher bleeding risk category. The control intervals depend on progression of liver disease. If aetiology or pathogenesis of further liver damage can be stopped, endoscopic follow-up every 3 years is sufficient [25]. Otherwise, patients should receive upper endoscopy every 1-2 years. Patients with small varices with either red wale signs or decompensated cirrhosis are candidates for NSBB, provided treatment is tolerated by the patient and there are no contraindications, which occur in around a quarter of patients [26]. Patients with large varices, especially with concomitant red wale signs, should receive NSBB or endoscopic band ligation (in case of intolerance or contraindications for NSBB) for prevention of first bleeding [22, 25]. NSBB reduce the risk of first bleeding from around 35 to $20 \%$ within 2 years [27]. Although the mechanism of both approaches is totally different (NSBB reduce portal venous tributary blood flow, while band ligation obliterates vessels with a high bleeding risk), there is no evidence that combining both - in contrast to secondary prophylaxis of bleeding - is superior to ligation or drug therapy alone. Both are equally effective with a trend in favour of ligation $[28,29]$. NSBB can be detrimental in patients with decompensated cirrhosis with low systolic blood pressure ( $<90 \mathrm{~mm} \mathrm{Hg}$ ), signs of kidney dysfunction (creatinine $>1.5 \mathrm{mg} / \mathrm{dL}$ ) and/or low cardiac output [22]. Here, NSBB should be stopped or the dosage reduced [30]. Although it is advised to titrate NSBB until a $25 \%$ reduction of basal heart rate has been reached, there is evidence that lower dosages may be equally effective $[20,28,31]$, probably with less side effects. Carvedilol, an NSBB with additional alpha-1 adrenoceptor blocking properties, induces a better haemodynamic response than propranolol and may prevent progression of varices [32]. It is also advised for primary prophylaxis of bleeding. The drug should be started with low dosages under careful supervision. Unfortunately, there is insufficient information to date as to whether standard hemodynamic control of response to NSBB improves management of primary prophylaxis.

Patients on NSBB for primary prophylaxis of variceal haemorrhage require no follow-up endoscopies as long as there are no signs of intestinal bleeding, while those receiving ligation do.

\section{Management of Acute Bleeding}

In the past decades, 30-day mortality of variceal bleeding has improved. It is now in the range of $10-20 \%$ [33].

Patients with liver cirrhosis who are suspected of bleeding from varices need immediate hemodynamic stabilization, careful transfusion up to a target haemoglobin not higher than 7-8 g/dL in order to prevent volume-induced rise of portal pressure, vasoactive drugs to reduce portal tributary flow, antibiotics (to blunt inflammatory stimuli) and endoscopy as soon as possible to define and treat the bleeding source under careful airway protection. Patients with compensated cirrhosis (Child A and bleeding) should receive standard treatment of variceal bleeding without TIPS. There is increasing evidence that preemptive TIPS placement using PTFE-covered stents achieves rapid and permanent haemostasis and improves survival in patients with active bleeding and decompensated liver cirrhosis [34, 35]. However, availability of this procedure is often limited. In patients with ascites, TIPS has the additional advantage of improving sodium excre- 
tion, which prevents the occurrence of ascites or treats any concurrent ascites. Preemptive early TIPS may also replace other risky bridging procedures, such as esophageal compression stents or balloon tamponade. Patients should be in a stable hemodynamic condition for this procedure.

\section{Prevention of Rebleeding Depending on Stage and Aetiology of Cirrhosis}

Patients in whom variceal bleeding has been treated successfully and who have reached day 5 after the acute event without further complications need rebleeding prophylaxis if no TIPS was inserted during the emergency period, since these patients have a $60-70 \%$ rebleeding risk within 2 years. This risk can be reduced to $45 \%$ by NSBB [36], by band ligation to around 30\% [37] and to around $25 \%$ by combined therapy. Thus, the combination of NSBB and repeat ligation until obliteration of varices is considered standard of care for rebleeding prophylaxis [22]. There is evidence that addition of NSBB or NSBB alone - besides their effect on bleeding prevention - reduce mortality [36-40] compared to band ligation as sole rebleeding prophylaxis. This beneficial effect on survival is most prominent in patients who show adequate reduction of portal pressure with NSBB [41]. Unfortunately, it has not yet been evaluated whether hemodynamic nonresponders profit from further application of NSBB in the setting of rebleeding prophylaxis or not [42]. There is evidence that patients with higher portal pressure show better hemodynamic response to NSBB than patients with low HVPG $(<10 \mathrm{~mm} \mathrm{Hg})$ [43]. It remains unclear whether the beneficial effects of NSBB on mortality are due to its portal pressure reducing effect or due to other postulated mechanisms, such as blunting inflammatory stimuli from the intestine [44]. Despite these positive effects, application of NSBB has to be considered with care in patients with hemodynamic instability and/or kidney dysfunction.

Insertion of TIPS is significantly more effective in the prevention of rebleeding than any other non-shunt procedure. However, this does not translate into a survival advantage and the better rebleeding prophylaxis occurs at the expense of a higher rate of overt encephalopathy [31, $45,46]$. Hepatic encephalopathy is lowered with the placement of covered small lumen stents [31, 47]. Given the positive effects of TIPS on improvement of kidney function, prevention of ascites and possible improvement of survival [48], TIPS placement should be considered a sec- ondary prophylaxis intervention especially in younger patients with high portal pressure and limited liver dysfunction. Whether TIPS placement should become standard initial treatment for variceal bleeding in all patients with decompensated cirrhosis needs to be further studied.

\section{Open Questions and Area for Further Research}

New concepts for the prevention of the formation of varices and first bleeding are mainly based on interrupting the aetiology of varices, or blunting inflammation and remodelling of the liver. For most of these strategies, adequate controlled trials are lacking. Here, we need more information.

With respect to acute bleeding and prevention of rebleeding, small lumen TIPS is very effective. Its insertion interrupts the risk of continuous and recurrent bleeding and prevents the formation of ascites or improves treatment of any co-existing ascites. But the quality of life is not improved when compared to the combination of drugs and/or ligation [31]. New or worsening of hepatic encephalopathy is the major concern of TIPS placement. A therapy that effectively prevents hepatic encephalopathy and targets concomitant inflammation in patients with liver cirrhosis would be an ideal accompaniment to TIPS. It is worthwhile for further clinical research to establish such a combined approach.

\section{Key Points}

1. Either NSBB or band ligation can be used as primary prophylaxis against variceal bleeding.

2. Acute variceal bleed should be treated with band ligation, combined with early TIPS in patients with severe liver dysfunction.

3. Secondary prophylaxis can be achieved with a combination of NSBB and band ligation.

4. Patients who are intolerant of NSBB should be evaluated for TIPS as secondary prophylaxis, especially if ascites is also present.

5. Use NSBB with caution in patients with hemodynamic compromise or baseline renal dysfunction!

6. NSBB are not used for preprimary prophylaxis of varices because there is not enough evidence that they blunt the formation of varices in early compensated liver cirrhosis. Here, the treatment of aetiology is key, and putative anti-fibrotic drugs may be tested. 


\section{References}

1 Kitano S, Terblanche J, Kahn D, Bornman PC: Venous anatomy of the lower oesophagus in portal hypertension: practical implications. Br J Surg 1986;73:525-531.

2 Spence RA, Sloan JM, Johnston GW, Greenfield A: Oesophageal mucosal changes in patients with varices. Gut 1983;24:10241029.

3 Vorobioff JD, Groszmann RJ: Hepatic venous pressure gradient measurement in pre-primary and primary prophylaxis of variceal hemorrhage. Ann Hepatol 2013;12:22-29.

4 Kleber G, Sauerbruch T, Ansari H, Paumgartner G: Prediction of variceal hemorrhage in cirrhosis: a prospective follow-up study. Gastroenterology 1991;100:1332-1337.

5 D’Amico G, Morabito A, D’Amico M, Pasta L, Malizia G, Rebora P, et al: Clinical states of cirrhosis and competing risks. J Hepatol 2018; 68:563-576

6 Williams R, Aspinall R, Bellis M, CampsWalsh G, Cramp M, Dhawan A, et al: Addressing liver disease in the UK: a blueprint for attaining excellence in health care and reducing premature mortality from lifestyle issues of excess consumption of alcohol, obesity, and viral hepatitis. Lancet 2014;384: 1953-1997.

7 Ginès P, Graupera I, Lammert F, Angeli P, Caballeria L, Krag A, et al: Screening for liver fibrosis in the general population: a call for action. Lancet Gastroenterol Hepatol 2016;1: 256-260.

8 Marcellin P, Gane E, Buti M, Afdhal N, Sievert W, Jacobson IM, et al: Regression of cirrhosis during treatment with tenofovir disoproxil fumarate for chronic hepatitis B: a 5-year open-label follow-up study. Lancet 2013;381: 468-475.

9 Toccaceli F, Laghi V, Capurso L, Koch M, Sereno S, Scuderi M, et al: Long-term liver histology improvement in patients with chronic hepatitis $\mathrm{C}$ and sustained response to interferon. J Viral Hepat 2003;10:126-133.

10 van der Meer AJ, Feld JJ, Hofer H, Almasio PL, Calvaruso V, Fernández-Rodríguez CM, et al: Risk of cirrhosis-related complications in patients with advanced fibrosis following hepatitis C virus eradication. J Hepatol 2017; 66:485-493.

11 Shah ND, Cots MV, Zhang C, Zahiragic N, Yu Y, Yacoub M, et al: Worldwide lack of early referral of patients with alcoholic liver disease: results of the global alcoholic liver disease survey (GLADIS). J Hepatol 2017; 66:S107-S108.

12 Åberg F, Helenius-Hietala J, Puukka P, Färkkilä M, Jula A: Interaction between alcohol consumption and metabolic syndrome in predicting severe liver disease in the general population. Hepatology 2018;67:2141-2149.

13 Lens S, Alvarado-Tapias E, Mariño Z, Londoño MC, LLop E, Martinez J, et al: Effects of all-oral anti-viral therapy on HVPG and systemic hemodynamics in patients with hepati- tis C virus-associated cirrhosis. Gastroenterology 2017;153:1273-1283.e1.

14 D’Ambrosio R, Aghemo A, Rumi MG, Ronchi G, Donato MF, Paradis V, et al: A morphometric and immunohistochemical study to assess the benefit of a sustained virological response in hepatitis $\mathrm{C}$ virus patients with cirrhosis. Hepatology 2012;56:532-543.

15 Turco L, Villanueva C, Mura VL, Garcia-Pagan JC, Reiberger T, Genesca J, et al: A reduction in the hepatic venous pressure gradient (HVPG) prevents clinical outcomes in compensated and decompensated cirrhosis: a meta-analysis. J Hepatol 2017;66:S103S104.

16 Tandon P, Abraldes JG, Berzigotti A, GarciaPagan JC, Bosch J: Renin-angiotensin-aldosterone inhibitors in the reduction of portal pressure: a systematic review and meta-analysis. J Hepatol 2010;53:273-282.

17 Schierwagen R, Uschner FE, Magdaleno F, Klein S, Trebicka J: Rationale for the use of statins in liver disease. Am J Physiol Gastrointest Liver Physiol 2017;312:G407-G412.

18 Vlachogiannakos J, Saveriadis AS, Viazis N, Theodoropoulos I, Foudoulis K, Manolakopoulos $\mathrm{S}$, et al: Intestinal decontamination improves liver haemodynamics in patients with alcohol-related decompensated cirrhosis. Aliment Pharmacol Ther 2009;29:992999.

19 Lim YL, Kim MY, Jang YO, Baik SK, Kwon SO: Rifaximin and propranolol combination therapy is more effective than propranolol monotherapy for the reduction of portal pressure: an open randomized controlled pilot study. Gut Liver 2017;11:702-710.

20 Schepke M, Wiest R, Flacke S, Heller J, StoffelWagner B, Herold T, et al: Irbesartan plus low-dose propranolol versus low-dose propranolol alone in cirrhosis: a placebo-controlled, double-blind study. Am J Gastroenterol 2008;103:1152-1158.

21 Groszmann RJ, Garcia-Tsao G, Bosch J, Grace ND, Burroughs AK, Planas R, et al: Betablockers to prevent gastroesophageal varices in patients with cirrhosis. N Engl J Med 2005; 353:2254-2261.

22 de Franchis R; Baveno VI Faculty: Expanding consensus in portal hypertension: Report of the Baveno VI Consensus Workshop: stratifying risk and individualizing care for portal hypertension. J Hepatol 2015;63:743-752.

23 Kleber G, Sauerbruch T, Fischer G, Paumgartner G: Pressure of intraoesophageal varices assessed by fine needle puncture: its relation to endoscopic signs and severity of liver disease in patients with cirrhosis. Gut 1989;30: 228-232.

24 North Italian Endoscopic Club for the Study and Treatment of Esophageal Varices: Prediction of the first variceal hemorrhage in patients with cirrhosis of the liver and esophageal varices. A prospective multicenter study. N Engl J Med 1988;319:983-989.
25 Bosch J, Sauerbruch T: Esophageal varices: stage-dependent treatment algorithm. J Hepatol 2016;64:746-748.

26 Schepke M, Kleber G, Nürnberg D, Willert J, Koch L, Veltzke-Schlieker W, et al: Ligation versus propranolol for the primary prophylaxis of variceal bleeding in cirrhosis. Hepatology 2004;40:65-72.

27 Poynard T, Calès P, Pasta L, Ideo G, Pascal JP, Pagliaro L, et al: Beta-adrenergic-antagonist drugs in the prevention of gastrointestinal bleeding in patients with cirrhosis and esophageal varices. An analysis of data and prognostic factors in 589 patients from four randomized clinical trials. Franco-Italian Multicenter Study Group. N Engl J Med 1991;324: 1532-1538.

28 Funakoshi N, Duny Y, Valats J-C, SégalasLargey F, Flori N, Bismuth M, et al: Metaanalysis: beta-blockers versus banding ligation for primary prophylaxis of esophageal variceal bleeding. Ann Hepatol 2012;11:369383.

29 Gluud LL, Krag A: Banding ligation versus beta-blockers for primary prevention in oesophageal varices in adults. Cochrane Database Syst Rev 2012;CD004544.

30 Reiberger T, Mandorfer M: Beta adrenergic blockade and decompensated cirrhosis. J Hepatol 2017;66:849-59.

31 Sauerbruch T, Mengel M, Dollinger M, Zipprich A, Rössle M, Panther E, et al: Prevention of rebleeding from esophageal varices in patients with cirrhosis receiving small-diameter stents versus hemodynamically controlled medical therapy. Gastroenterology 2015;149: 660-668.e1.

32 Sauerbruch T, Schierwagen R, Trebicka J: Managing portal hypertension in patients with liver cirrhosis. F1000Res 2018;7:533.

33 Jairath V, Rehal S, Logan R, Kahan B, Hearnshaw S, Stanworth S, et al: Acute variceal haemorrhage in the United Kingdom: patient characteristics, management and outcomes in a nationwide audit. Dig Liver Dis 2014;46: 419-426

34 García-Pagán JC, Caca K, Bureau C, Laleman W, Appenrodt B, Luca A, et al: Early use of TIPS in patients with cirrhosis and variceal bleeding. N Engl J Med 2010;362:2370-2379.

35 Lv Y, Zuo L, Zhu X, Zhao J, Xue H, Jiang Z, et al: Early-TIPS improves survival in cirrhotic patients with high-risk varical bleeding: results of a China multicenter observational study. J Hepatol 2018;68:S78-S79.

36 Bernard B, Lebrec D, Mathurin P, Opolon P, Poynard T: Beta-adrenergic antagonists in the prevention of gastrointestinal rebleeding in patients with cirrhosis: a meta-analysis. Hepatology 1997;25:63-70.

37 Thiele M, Krag A, Rohde U, Gluud LL: Metaanalysis: banding ligation and medical interventions for the prevention of rebleeding from oesophageal varices. Aliment Pharmacol Ther 2012;35:1155-1165. 
38 Krag A, Wiest R, Gluud LL: 168 reduced mortality with non-selective betablockers compared to banding is not related to prevention of bleeding or bleeding related mortality: systematic review of randomized trials. J Hepatol 2011;54:S72.

39 Li L, Yu C, Li Y: Endoscopic band ligation versus pharmacological therapy for variceal bleeding in cirrhosis: a meta-analysis. Can J Gastroenterol 2011;25:147-155.

40 Pfisterer N, Dexheimer C, Fuchs E-M, Bucsics T, Schwabl P, Mandorfer M, et al: Betablockers do not increase efficacy of band ligation in primary prophylaxis but they improve survival in secondary prophylaxis of variceal bleeding. Aliment Pharmacol Ther 2018;47:966979.

41 Villanueva C, Graupera I, Aracil C, Alvarado E, Miñana J, Puente Á, et al: A randomized trial to assess whether portal pressure guided therapy to prevent variceal rebleeding improves survival in cirrhosis. Hepatology 2017; 65:1693-1707.

42 Sauerbruch T: Continuation of nonselective beta-blockers for patients with liver cirrhosis and hemodynamic nonresponse? Hepatology 2017;66:1362-1363.

43 Villanueva C, Albillos A, Genescà J, Abraldes JG, Calleja JL, Aracil C, et al: Development of hyperdynamic circulation and response to $\beta$-blockers in compensated cirrhosis with portal hypertension. Hepatology 2016;63: 197-206.

44 Tsochatzis EA, Bosch J, Burroughs AK: New therapeutic paradigm for patients with cirrhosis. Hepatology 2012;56:1983-1992.

45 Khan S, Tudur Smith C, Williamson P, Sutton R: Portosystemic shunts versus endoscopic therapy for variceal rebleeding in patients with cirrhosis. Cochrane Database Syst Rev 2006;4:CD000553.

46 Holster IL, Tjwa ETTL, Moelker A, Wils A, Hansen BE, Vermeijden JR, et al: Covered transjugular intrahepatic portosystemic shunt versus endoscopic therapy $+\beta$-blocker for prevention of variceal rebleeding. Hepatology 2016;63:581-589.

47 Wang Q, Lv Y, Bai M, Wang Z, Liu H, He C, et al: Eight millimetre covered TIPS does not compromise shunt function but reduces hepatic encephalopathy in preventing variceal rebleeding. J Hepatol 2017;67:508-516.

48 Salerno F, Cammà C, Enea M, Rössle M, Wong F: Transjugular intrahepatic portosystemic shunt for refractory ascites: a metaanalysis of individual patient data. Gastroenterology 2007;133:825-834. 